\title{
Perbaikan Pertumbuhan dan Hasil Kacang Tanah di Tanah Entisol Semiarid melalui Aplikasi Biochar
}

\author{
Arnoldus Klau Berek ${ }^{a}$, Prisila O. Tabati ${ }^{\mathrm{b}}$, Ursulina Uto Keraf ${ }^{\mathrm{b}}$, Edmundus Bere ${ }^{\mathrm{b}}$, Remegius Taekab ${ }^{\mathrm{b}}$, dan Ardianus Wora ${ }^{\mathrm{b}}$ \\ ${ }^{a}$ Pusat Studi Lahan Kering, Fakultas Pertanian, Universitas Timor, Kefamenanu, TTU - NTT, Indonesia. \\ ${ }^{b}$ Fakultas Pertanian, Universitas Timor, Kefamenanu, TTU - NTT, Indonesia.
}

\section{Article Info}

Article history:

Received 29 Februari 2017

Received in revised form 20 April 2017

Accepted 9 Juni 2017

\section{Keywords:}

Tanah Entiso

Biochar Sekam Padi

Kayu Putih

Kirinyu

Kacang Tanah

\section{Abstrak}

Produktivitas kacang tanah di tanah Entisol (lithic subgroup) semiarid di wilayah Timor Barat sangat rendah karena solum tanahnya sangat tipis, kandungan bahan organik sangat rendah, retensi air dan haranya pun rendah. Tujuan penelitian ini adalah untuk memperbaiki produktivitas kacang tanah di tanah Entisol melalui aplikasi biochar. Tiga jenis biochar yakni sekam padi, kayu putih dan jerami kirinyu yang diproduksi pada suhu $290-320^{\circ} \mathrm{C}$ diberikan pada tanah Entisol dengan takaran 0, 5 dan 10 t/ha, diinkubasikan selama 30 hari dan ditanami dengan kacang tanah varietas lokal. Setiap petak percobaan, kecuali kontrol, diberikan 5 t/ha pupuk kandang sebagai sumbe unsur hara. Semua kombinasi perlakukan disusun dalam sebuah rancangan acak kelompok faktorial 3 x 3 dan diulang melalui 4 blok. Hasil penelitian menunjukkan bahwa hasil kacang tanah (berat kering polong) meningkat 50-100\% dibandingkan dengan kontrol melalui pemberian biochar 5-10 t/ha. Pemberian biochar juga meningkatkan total polong dan jumlah polong berbiji 2 dan 3, tinggi tanaman, diameter batang, luas daun, jumlah bintil akar, dan berat kering tanaman. Efek jenis biochar terhadap pertumbuhan dan hasil kacang tanah secara berurutan adalah sekam padi > kirinyu > kayu putih, sedangkan dari aspek takaran, secara umum 10 t/ha lebih tinggi dari pada 5 t/ha. Perbaikan produktivitas kacang tanah oleh pemberian biochar tersebut kemungkinan disebabkan oleh efek langsung pada tan aman atau perbaikan produktivitas tanah Entisol. Secara umum, pemberian biochar sekam padi, kirinyu dan kayu putih pada tanah Entisol semiarid dapat memperbaiki produktivitas tanah dan karenanya meningkatkan hasil kacang tanah. (02017 dipublikasikan oleh Savana Cendana.

\section{Pendahuluan}

Tanah di sekitar kampus Univertas Timor, Kefamenanu, TTU, NTT, diklasifikasikan sebagai tanah litosol atau Entisol (Soil Survey Staff, 2014), yang solum tanahnya sangat tipis (lithic), kandungan bahan organik sangat rendah, kapasitas tukar kation sangat rendah, kapasitas retensi air dan hara sangat terbatas sehingga kurang mendukung pertumbuhan tanaman seperti kacang tanah.

Biochar adalah produk padat pirolisis, kaya karbon, hasil konversi biomassa secara termokimia di dalam wadah tanpa oksigen atau suplai oksigen terbatas. Biochar dapat digunakan secara luas sebagai agen untuk memperbaiki tanah, meningkatkan efisiensi penggunaan sumberdaya, remediasi dan/atau proteks melawan polusi lingkungan dan sebagai agen mitigasi gas rumah kaca (Lehmann \& Joseph, 2015). Hasil-hasil penelitian terkini, mengindikasikan bawa biochar memiliki porositas yang tinggi (Downie et al., 2009), luas dan muatan permukaan yang tinggi sehingga dapat memperbaiki sruktur tanah, bobot volume tanah, meningkatkan kapasitas tanah menyimpan air dan hara (Baronti et al., 2014) dapat menambah unsur hara (Biederman \& Harpole, 2013; Ding et al. 2016), dan juga menjadi hunian yang aman dan nyaman bagi organisme tanah (Lehmann et al., 2011). Lebih dari itu, biochar lebih stabil bertahan di dalam tanah dibandingkan dengan bahan pembenah tanah lainnya sehingga fungsinya di dalam tanah bersifat jangka panjang (Wang et al., 2016).

Biochar secara langsung memberikan efek pada tanaman kacang-kacangan seperti meningkatkan fiksasi $\mathrm{N}$ biologis (Rondon et al., 2007; Mia et al., 2014), meningkatkan toleransi kekeringan (pertumbuhan, efisiensi penggunaan air dan hubungan antara tanah-tanaman (emisi gas $\mathrm{N}_{2} \mathrm{O}$ tanah) (Kammann et al., 2011), dan meningkatkan potensial air daun (Baronti et al., 2014).

Aplikasi biochar di tanah Entisol diproyeksikan akan memperbaiki sifat fisika dan kimia tanah seperti bobot volume (kegemburan) tanah, kapasitas ika air, KTK, kandungan karbon/bahan organik tanah, kemampuan menahan unsu hara terhadap pelindian, dan tambahan unsur hara walaupun terbatas. Jika ke dalam tanah Entisol juga ditambahkan pupuk kandang, maka kekurangan hara yang disuplai tanah dan biochar dapat dicukupi. Dengan demikian aplikasi biochar pada tanah Entisol yang telah diberi pupuk kandang diharapkan dapa meningkatkan produktivitas tanah dan selanjutnya dapat meningkatkan pertumbuhan dan hasil kacang tanah.

Tujuan penelitian ini adalah untuk mendapatkan jenis dan takaran biochar yang tepat bagi perbaikan produktivitas tanah Entisol dan kacang tanah.

\section{Metode}

Percobaan lapangan dilakukan pada puncak musim kemarau (SeptemberNovember 2016) di Kebun Percobaan Fakultas Pertanian, Universitas Timor Kelurahan Sasi, Kecamatan Kota, Kefamennu, TTU, NTT, Indonesia. Jenis tanahnya adalah Entisol dengan tingkat erosi parit sehingga solum tanahnya sangat tipis (tidak dijumpai horizon permukaan), vegetasi dominan adalah kayu putih (Eucalyptus alba) dan rumput alam yang hanya tumbuh pada musim hujan (4 bulan) sehingga bahan organik tanahnya sangat rendah.

Biochar dibuat menggunakan alat Kontiki. Sekam padi, kayu putih dan jerami kirinyu, dikumpullkan, dikeringkan dan dibakar pada suhu $290-320^{\circ} \mathrm{C}$. Biochar hasil pirolisis didinginkan, dikeringkan, dihaluskan dan diayak lolos ayakan $2 \mathrm{~mm}$ untuk analisis dan lolos ayakan $4 \mathrm{~mm}$ untuk aplikasi di lahan.

Pupuk kandang sapi matang dikumpulkan dari kandang sapi masyarakat di Noemuti, dibersihkan dari bahan-bahan pengotor, diayak lolos ayakan $4 \mathrm{~mm}$ dan disimpan sebelum diaplikasikan.

Benih kacang tanah vaeritas unggul lokal dikoleksi dari benih yang disimpan masyarakat satu tahun yang akan digunakan pada musim tanam berikut. Benih dikupas dan diseleksi untuk mendapat ukuran yang seragam.
Lahan percobaan dibersihkan dari gulma dan vegetasi lainnya, diolah, dibiarkan seminggu, dibuat bedeng berukuran $240 \mathrm{~cm}$ x $160 \mathrm{~cm}$, dan diberi label, dan dikuti dengan aplikasi biochar.

Penelitian ini menggunakan Rancangan Acak Kelompok (RAK) faktorial 3 x 3 yang diulang 4 kali. Faktor pertama adalah jenis biochar yakni : sekam padi (SP), kirinyu (KR), dan kayu putih (KP). Faktor ke dua adalah takaran biochar, yakni tanpa biochar (0), biochar $5 \mathrm{t} / \mathrm{ha}(5)$ dan biochar $10 \mathrm{t} / \mathrm{ha}(10)$

Biochar dan pupuk kandang sapi diberikan ke dalam tanah dengan cara dibenamkan dalam tanah bersamaan dengan pengolahan tanah dengan takaran sesuai perlakuan. Pada empat petak percobaan tidak diberikan pupuk maupun biochar (kontrol), empat petak percobaan hanya diberikan pupuk kandang sapi 5 t/ha $(1,92 \mathrm{~kg} /$ petak $)$ tanpa biochar. Semua petak yang diberi biocha ditambahkan pupuk kandang sapi $5 \mathrm{t} / \mathrm{ha}(1,92 \mathrm{~kg} / \mathrm{petak})$. Takaran biochar untuk setiap petak adalah setiap jenis biochar yaitu $5 \mathrm{t} / \mathrm{ha}(1,92 \mathrm{~kg} /$ petak $)$ dan $10 \mathrm{t} / \mathrm{h}$ $(3,84 \mathrm{~kg} /$ petak $)$, sehingga setiap 4 petak diberikan biochar sekam padi, kayu put dan kirinyu 5 dan 10 t/ha. Total kebutuhan pupuk kandang sapi sebanyak 53,76 $\mathrm{kg}$ dan total setiap jenis biochar yang dibutuhkan adalah 46,08 $\mathrm{kg}$ untuk setiap jenis. Setelah diberikan pupuk dan bichar, tanah disiram dan diinkubasikan selama 4 minggu sebelum ditanami.

Penanaman dilakukan pada pagi hari tanggal 25 Oktober 2016, dengan cara tugal sedalam $\pm 3 \mathrm{~cm}$. Jumlah benih yang ditanam per lubang adalah dua biji. Jarak tanam yang digunakan $40 \mathrm{~cm}$ x $20 \mathrm{~cm}$. Jumlah barisan dalam petak adalah 4 dan setiap baris terdiri dari 12 lubang tanam sehingga jumlah tanaman setiap petak adalah 48 tanaman dan jumlah tanaman kacang tanah keseluruhannya adalah 1.536 tanaman. Selanjutnya, tanaman disiram, secara rutin, dilakukan penyiangan, penggemburan serta pengendalian hama dan penyakit. Penyiraman dilakukan pada pagi dan sore hari hingga tanah mengalami kecukupan air dengan menggunakan gembor hingga tanaman berumur 1,5 bulan. Selanjutnya penyiraman dikurangi hanya sekali sehari. Penyiangan dilakukan terhadap gulma yang tumbuh di petak percobaan dan dilakukan secara manual. Penggemburan dilakukan 2 kali, pada penggemburan ke dua disertai juga dengan pembumbunan

Panen kacang tanah dilakukan ketika tanaman mencapai \pm 95 hari setelah tanam dengan menunjukkan ciri-ciri daun mulai mengering. Panen dilakukan dengan cara disiram terlebih dahulu, diikuti dengan pencabutan tanaman dan penggalian jika terdapat polong yang tertinggal di dalam tanah.

Parameter yang diamati meliputi tinggi tanaman, diameter batang, jumlah daun, luas daun, bintil akar, berat kering tanaman, panjang akar, jumlah polong, jumlah biji per polong dan berat kering polong.

\section{Hasil dan Pembahasan}

\subsection{Pertumbuhan Tanaman}

Pertumbuhan kacang tanah di tanah Entisol yang dinyatakan dalam parameter tinggi tanaman, diameter batang, jumlah daun, luas daun, total bintil akar, panjang akar dan total berat kering per tanaman yang diukur pada 42 hari setelah tanam (HST) dicantumkan di Tabel

Data pertumbuhan tanaman baik pada bagian trubus (tinggi, diameter batang, jumlah daun, luas daun,) maupun pada bagian akar (panjang akar, jumlah bintil akar) menunjukkan bahwa terdapat perbaikan/peningkatan pertumbuhan kacang tanah dengan pemberian biochar. Jenis biochar secara signifikan berpengaruh terhadap hampir semua parameter pertumbuhan, dengan urutan terbaik adalah sekam padi $>$ seresah kirinyu $>$ kayu putih. Takaran biochar juga secara signifikan mempengaruhi pertumbuhan kacang tanah. Takaran 10 t/ha meningkatan pertumbuhan kacang tanah lebih baik dari pada 5 t/ha atau hanya diberi pupuk kandang 5 t/ha dan yang paling rendah adalah kontrol (tanpa biochar), kecuali biochar kayu putih yang cenderung efeknya menurun ketika takarannya ditingkatkan hingga 10 t/ha. Efek serupa dilaporkan oleh Gao et al. (2017) bahwa pemberian biochar dapat meningkatkan tinggi, berat daun dan akar serta kandungan klorofil kacang tanah. 
Data tersebut mengindikasikan efek pemberian biochar pada tanaman secara langsung seperti penambahan unsur hara, namun juga melalui perbaikan produktivitas tanah Entisol. Hal ini dikaitkan dengan fungsi biochar dalam memperbaiki kapasitas tanah meretensi air dan hara, struktur tanah (menggemburkan tanah) sehingga akar tanaman lebih mudah berkembang di dalam tanah (akar tanaman lebih panjang), memperbaiki aerasi dan porositas tanah sehingga respirasi akar dan kehidupan mikroba bermanfaat seperti rhizobium lebih tinggi (jumlah bintil akar meningkat dengan pemberian biochar).

Tabel 1. Efek Biochar pada Pertumbuhan Tanaman Kacang Tanah Diukur pada 42 Hari Setelah Tanam.

\begin{tabular}{|c|c|c|c|c|c|c|c|}
\hline Perlakuan & $\begin{array}{l}\text { Tinggi Tanaman } \\
(\mathrm{cm})\end{array}$ & $\begin{array}{c}\text { Diameter } \\
\text { Batang }(\mathrm{mm})\end{array}$ & $\begin{array}{l}\text { Jumlah Daun } \\
\text { (helai) }\end{array}$ & $\begin{array}{l}\text { Luas Daun } \\
\left(\mathrm{cm}^{2}\right)\end{array}$ & $\begin{array}{c}\text { Total Bintil } \\
\text { Akar (bintil) }\end{array}$ & $\begin{array}{l}\text { Panjang Akar } \\
(\mathrm{cm})\end{array}$ & $\begin{array}{c}\text { Berat Kering Per } \\
\text { Tanaman }(\mathrm{g})\end{array}$ \\
\hline Kontrol & $16,6 \pm 1,2 d$ & $2,2 \pm 0,2 \mathrm{c}$ & $84 \pm 2,1 \mathrm{~d}$ & $520,0 \pm 8,2 d$ & $80 \pm 2,5 \mathrm{~d}$ & $15,8 \pm 0,8 \mathrm{~d}$ & $9,8 \pm 0,4 \mathrm{~d}$ \\
\hline Pupuk kandang 5 t/ha & $16,9 \pm 1,3 \mathrm{~d}$ & $2,2 \pm 0,1 \mathrm{c}$ & $90 \pm 1,2 \mathrm{c}$ & $593,6 \pm 10,2 \mathrm{c}$ & $121 \pm 2,8 \mathrm{c}$ & $18,5 \pm 0,4 \mathrm{c}$ & $10,2 \pm 0,3 \mathrm{c}$ \\
\hline Sekam padi $5 \mathrm{t} / \mathrm{ha}$ & $21,3 \pm 0,9 b$ & $2,3 \pm 0,3 b$ & $117 \pm 2,0 \mathrm{~b}$ & $737,6 \pm 9,8 b$ & $137 \pm 2,7 \mathrm{~b}$ & $21,1 \pm 0,6 b$ & $12,6 \pm 0,2 b$ \\
\hline Sekam padi 10 t/ha & $23,6 \pm 1,0 \mathrm{a}$ & $2,4 \pm 0,2 \mathrm{a}$ & $128 \pm 1,5 \mathrm{a}$ & $963,5 \pm 9.7 \mathrm{a}$ & $167 \pm 2,6 \mathrm{a}$ & $23,0 \pm 0,5 \mathrm{a}$ & $16,2 \pm 0,3 \mathrm{a}$ \\
\hline Kayu putih $5 \mathrm{t} / \mathrm{ha}$ & $18,7 \pm 1,2 \mathrm{c}$ & $2,4 \pm 0,1 \mathrm{a}$ & $115 \pm 1,8 b$ & $784,4 \pm 8,9 b$ & $128 \pm 3,1 \mathrm{c}$ & $21,1 \pm 0,3 b$ & $13,6 \pm 0,4 b$ \\
\hline Kayu putih $10 \mathrm{t} / \mathrm{ha}$ & $20,1 \pm 1.0 \mathrm{~b}$ & $2,2 \pm 0,1 \mathrm{c}$ & $104 \pm 2.0 \mathrm{c}$ & $710,1 \pm 10,6 b$ & $113 \pm 2,2 \mathrm{c}$ & $20,5 \pm 0,5 b$ & $10,9 \pm 0,2 \mathrm{c}$ \\
\hline Kirinyu 5 t/ha & $18,0 \pm 0,7 \mathrm{c}$ & $2,3 \pm 0,2 b$ & $100 \pm 2,1 \mathrm{c}$ & $604,4 \pm 10,7 \mathrm{c}$ & $125 \pm 2,6 \mathrm{c}$ & $20,0 \pm 0,4 b$ & $11,4 \pm 0,2 \mathrm{c}$ \\
\hline Kirinyu $10 \mathrm{t} / \mathrm{ha}$ & $20,2 \pm 0,8 \mathrm{~b}$ & $2,3 \pm 0,1 \mathrm{a}$ & $121 \pm 1,5 \mathrm{a}$ & $833,8 \pm 8,9 b$ & $166 \pm 2,7 \mathrm{a}$ & $21,9 \pm 0,3 b$ & $14,0 \pm 0,3 \mathrm{~b}$ \\
\hline
\end{tabular}

\subsection{Hasil dan Komponen Hasil}

Efek biochar terhadap hasil dan komponen hasil kacang tanah ditunjukkan melalui data bintil akar efektif, jumlah polong per tanaman, jumlah biji per polong, dan berat kering polong sebagaimana diilustrasikan pada Gambar 1, 2, 3 , dan 4 .

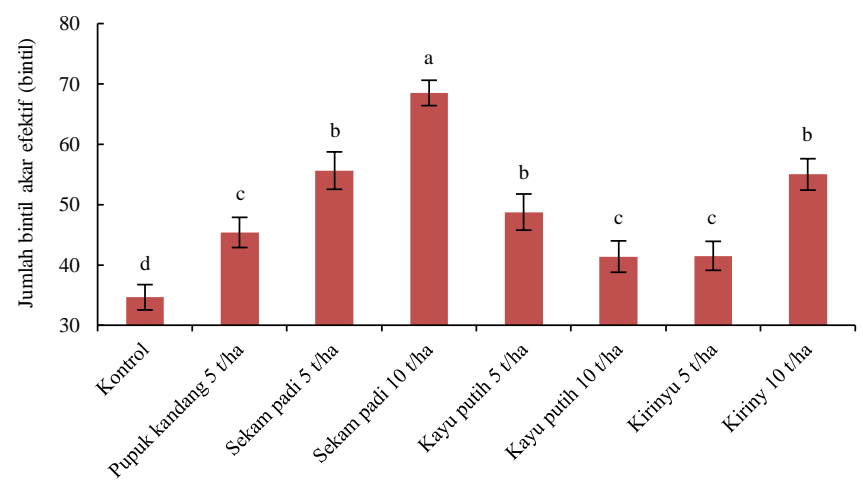

Gambar 1. Efek Biochar pada Jumlah Bintil Akar Efektif Kacang Tanah Varietas Lokal

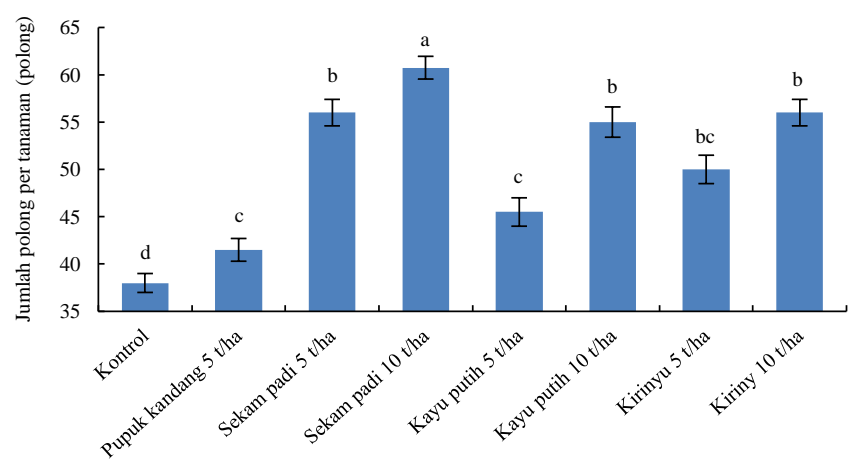

Gambar 2. Efek Biochar terhadap Jumlah Polong Per Tanaman Kacang Tanah Varietas Lokal

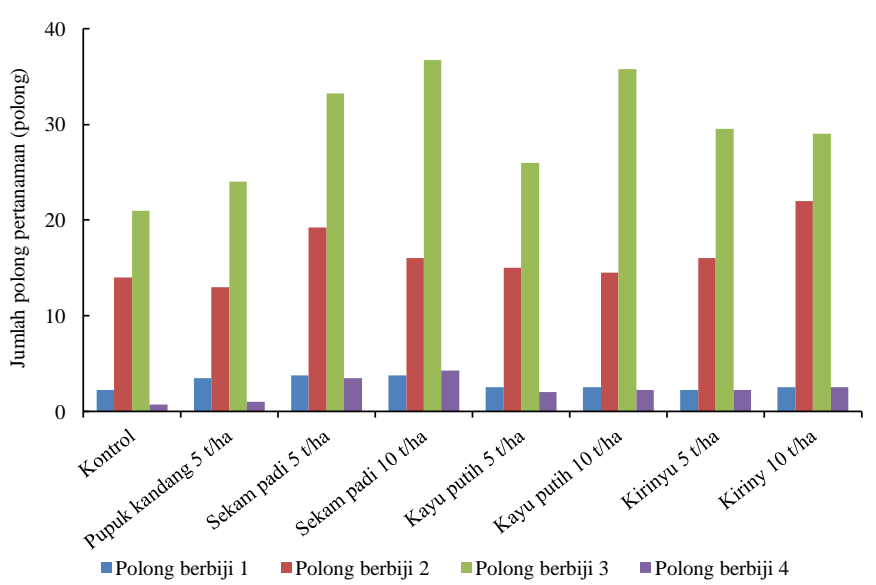

Gambar 3. Efek Biochar terhadap Jumlah Biji Per Polong Kacang Tanah Varietas Lokal

Tampak sangat jelas bahwa biochar sekam padi $10 \mathrm{t} / \mathrm{ha}$ memberikan efek terbaik pada komponen dan hasil kacang tanah di tanah Entisol, diikuti oleh biochar kirinyu dan kayu putih. Efek kayu putih takaran 10 t/ha pada hasil (Gambar 2. dan 4.) lebih tinggi dari pada takaran 5 t/ha dibandingkan dengan pertumbuhan kacang tanah mungkin karena proses dekomposisinya yang lebih lambat dibandingkan dengan biochar lainnya. Hasil kacang tanah berupa berat polong kering mencapai 3,7 t/ha setelah diberi biochar sekam padi $10 \mathrm{t} / \mathrm{ha}$. Hasil tersebut lebih dari 2 kali lipat hasil kacang tanah tanpa biochar (1,6 t/ha). Hasil yang relatif sama dilaporkan oleh Xu et al. (2015) yang menanam kacang tanah di tanah ferrosol dan redoxi-hydrosol Australia yang diberi biochar 85 t/ha.

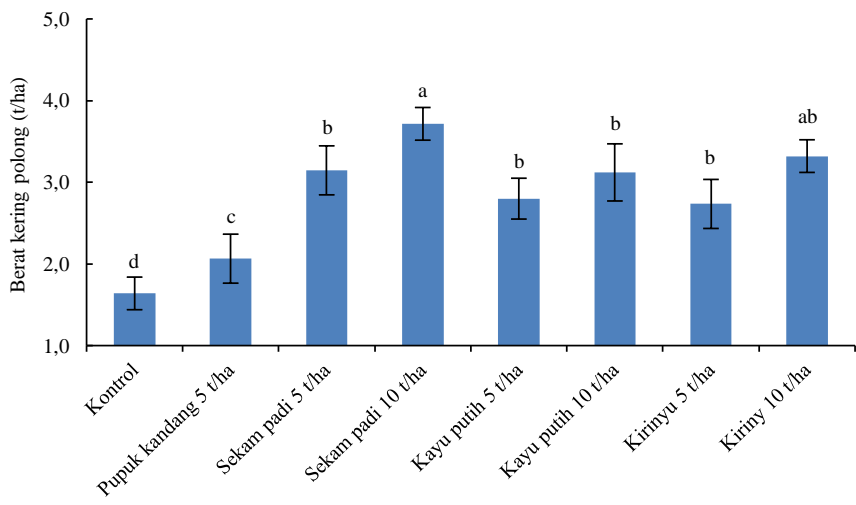

Gambar 4. Efek Biochar terhadap Berat Kering Polong Kacang Tanah Varietas Lokal

Efek pemberian biochar yang menarik adalah terhadap jumlah biji per polong (Gambar 3.). Pemberian biochar dalam memacu peningkatan jumlah polong berbiji 2 dan polong berbiji 3 lebih nyata dibandingkan dengan jumlah polong berbiji tunggal atau berbiji 4 .

\section{Simpulan}

Pemberian biochar pada tanah Entisol semiarid dapat meningkatkan pertumbuhan (tinggi tanaman, diameter batang, jumlah dan luas daun, berat kering total dan jumlah bintil akar) dan hasil kacang tanah varietas lokal (jumlah polong berbiji 2 dan 3, dan berat kering polong) jika dibandingkan dengan pemberian pupuk kandang saja atau tanpa perlakukan. Jenis biochar berpengaruh secara signifikan terhadap pertumbuhan dan hasil kacang tanah varietas lokal dengan urutan biochar sekam padi > kirinyu > kayu putih. Takaran biochar secara nyata berpengaruh terhadap pertumbuhan dan hasil kacang tanah varietas lokal di tanah Entisol. Secara umum takaran 10 t/ha lebih baik dibandingkan dengan takaran 5 t/ha. Pemberin biochar sekam padi 10 t/ha pada tanah Entisol semiarid meningkatkan hasil kacang varietas lokal dari 1,6 t/ha menjadi 3,7 t/ha.

\section{Pustaka}

Baronti, S., Vaccari, F.P., Miglietta, F., Calzolari, C. Lugato, E., Orlandini, S., Pini, R., Zulian, C., Genesio, L. 2014. Impact of biochar application on plant water relations in Vitis vinifera L. Europ. J. Agron. 53:38-44.

Biederman, L. A., Harpole, W. T. 2013. Biochar and its effects on plant productivity and nutrient cycling: a meta-analysis. GCB Bioenergy. 5: 202214.

Ding, Y., Liu, Y., Liu, S., Li, Z., Tan, X., Huang, X., Zeng, G. 2016. Biochar to improve soil fertility. A review. Agron. Sustain. Dev. 36: 2-18.

Downie, A., Munro, P., Grosky, A. 2009. Characterization of biochar-physical and structural properties. In: Lehmann \& Joseph (eds). 2009. Biochar for environmental management: science and technology. Earthscan. p 13-29.

Gao, M., Liu, X., Li, N., Luo, P., Han, X., Yang, J. 2017. The impact of application of biocar on peanuts growing. IOP Conf. Ser.: Mater. Sci. Eng. 274012156.

Kammann, C.I., Linsel, S., Gößling, J.W., Koyro, H-W. 2011. Influence of biochar on drought tolerance of Chenopodium quinoa Willd and on soilplant relations. Plant Soil. 345: 195-210.

Lehmann, J., Joseph, S. 2015. Biochar for Environmental Management: An Introduction. In: Biochar for Environmental Management - Science and Technology, 2nd edition. J. Lehmann and S. Joseph (eds.). Routledge. 
Lehmann, J., Rillig, M.C., Thies, J., Marsiello, C.A., Hockaday, W.C., Crowley,

D. 2011. Biochar effects on soil biota e A review. Soil Biol. Biochem. 43 $1812-1836$.

Mia, S., van Groenigena, J.W., van de Voorde, T.F.J., Orama, N. J., Bezemer, T.M., Mommer, L., Jeffery, S. 2014. Biochar application rate affects biological nitrogen fixation in red clover conditional on potassium availability. Agric. Ecosyst. Environ. 191: 83-91

Rondon, M.A., Lehmann J., Ramírez, J. Hurtado M. 2007. Biological nitrogen fixation by common beans (Phaseolus vulgaris L.) increases with bio-char additions. Biol. Fertil. Soils. 43:699-708

Soil Survey Staff. 2014. Keys to soil taxonomy. USDA. USA.

Xu, C.Y., Hosseini-Bai, S., Hao, Y., Rachaputi, R.C., Wang, H., Xu, Z., Wallace, H. 2015. Effect of biochar amendment on yield and photosynthesis of peanut on two types of soils. Environ. Sci. Pollut. Res. Int. 22: 6112-6125.

Wang, J., Xiong, Z., Kuzyakov, Y. 2016. Biochar stability in soil: meta-analysis of decomposition and priming effects. GCB Bioenergy. 8: 512-523. 